\title{
Interventions to improve in-hospitals cardiac arrest (IHCA) survival rate - a single center report
}

Lalande M., Burtin P., Bigeon J.Y., Courant P., Halchini C., Roussiaux A. Clinique du Millénaire, Dept of Anesthesiology and Intensive Care, Montpellier, France

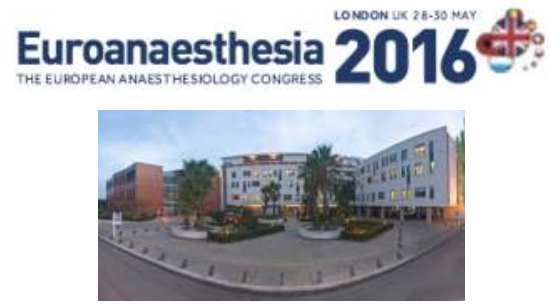

\section{INTRODUCTION}

In 2005, french Guidelines promoted interventions to improve survival after IHCA (1). We developped a program aimed at following these guidelines and kept a local registry of IHCA.

Our objective was to report on the effect of this program on IHCA survival over the last 7 years.

\section{METHODS}

All IHCA were recorded on a database. Interventions were: creations of a code number, $100 \%$ AED availability on wards, 2 successive code carts modifications (CCM), implementation of a staff education program. Moreover, three changes occured in medical activity and architecture of the structure during the period. We retrospectively analysed the database over 13 half year categories. Chi-square test for trends was used to determine statistical significance of change in survival rate.

\section{RESULTATS}

393 IHCA patients were treated from $01 / 01 / 09$ to $30 / 06 / 15$. Overall mean value were : age $71 \pm 11$, non shockable rythms $56,7 \%$, time to CPR 1,29min, immédiate survival (IS) 66,2\%, hospital survival (HS) $44,8 \%$ (fig1). Temporal trend showed an increased IS and HS over a 7 years time period (fig2). Significant improvement in IS was reached after complete staff education. HS increase was reached after creation of the code number. No other intervention achieved statistically significant changes. Survival decrease was observed after each structural changes (SC) in the institution (fig3).

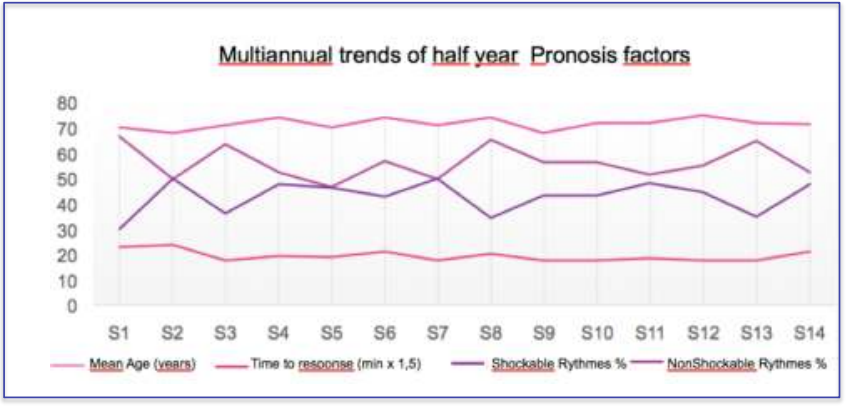

Figure l: Survival Pronosis factors

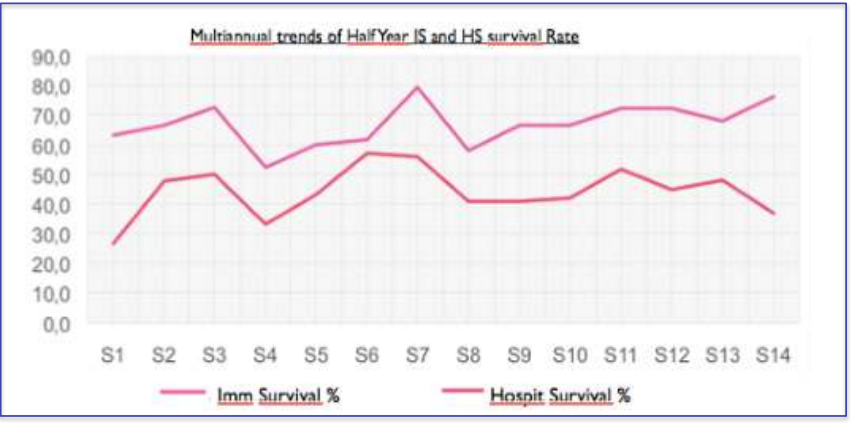

Figure2 Immediate and Hospital survival

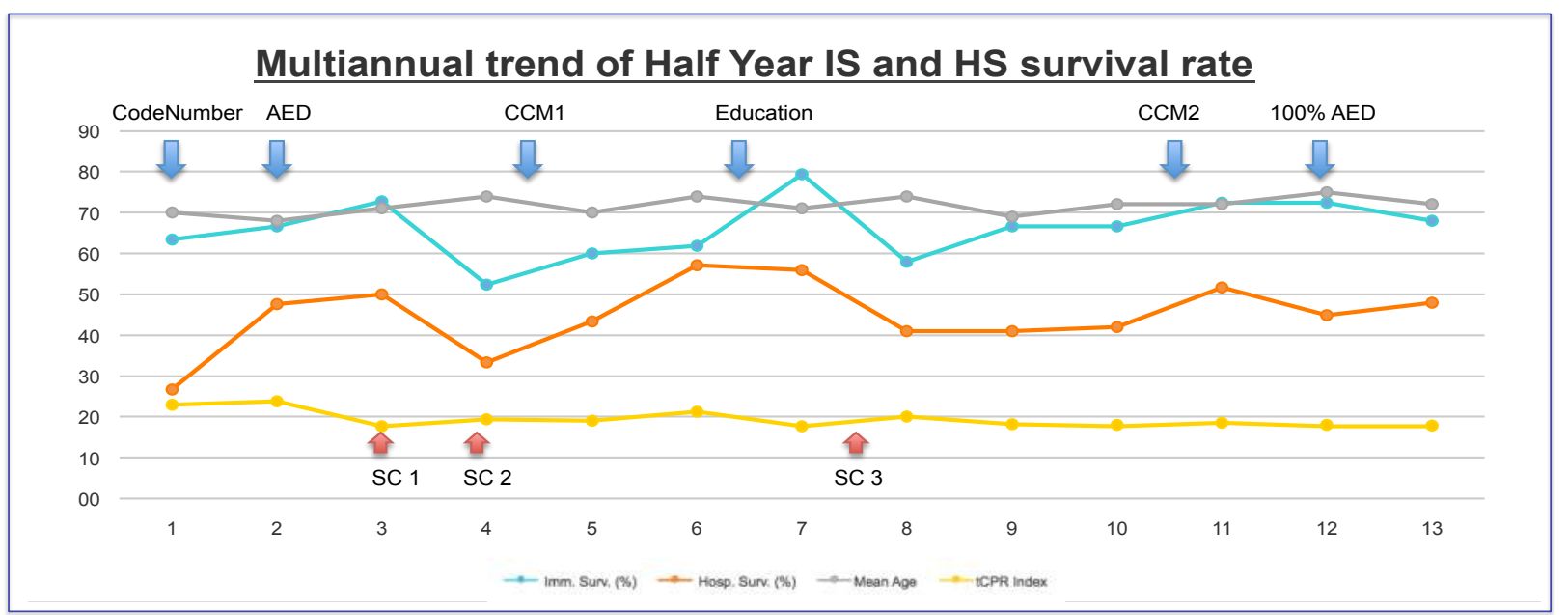

Figure3 Trends of Immediate Survival and Hospital Survival according to interventions

\section{DISCUSSION}

Guidelines implementation improved HS in the institution: it increased over time and never went lower than before intervention (2)(3).

All interventions weren't beneficial. The massive staff education program provided the largest increase in immediate survival rate although this increase was not sustained.

The decrease in survival rates observed after each change in the institution suggest that structural risk factors may account to explain the survival rate variability.

Continuous monitoring of the survival rate of IHCAs cases is a useful tool in order to implement or priorize interventions at an institution level.

References:

1/ Recommandations pour l'organisation de la prise en charge des urgences vitales intrahospitalières, Conférence d'experts, SFAR 2004

2/ Trends in survival after in-hospital cardiac arrest, Girotra S., NEJM, 2013 Feb 14

3/ Rapid response team and hospital mortality in hospitalized patients, Jung B., Intensive Care medicine, 2016 April 